\title{
Dosagem de Folatos Maternos e Fetais, Séricos e Eritrocitários em Malformações por Defeito de Fechamento do Tubo Neural no Feto
}

\author{
Maternal and Fetal Serum and Red Blood Cell Folate Levels in \\ Pregnancies Complicated by Neural Tube Defects
}

\author{
Victor Bunduki, Silvio Martinelli, Fábio R. Cabar, Seizo Miyadahira \\ Marc Dommergues, Yves Dumez, Marcelo Zugaib
}

\begin{abstract}
RESUM0
Objetivos: avaliar os níveis de folatos maternos e fetais gestações com malformações por defeitos de fechamento do tubo neural (DFTN).

Métodos: o estudo foi do tipo caso-controle, no qual 14 casos de fetos com DFTN (grupo estudo) e 14 casos de fetos com outras malformações (grupo controle) foram estudados em gestantes de baixo risco para DFTN. Propusemo-nos a dosar o ácido fólico, na sua forma total e metilada, nos compartimentos fetal e materno, utilizando dosagens séricas e tissulares (eritrocitárias), assim como o volume corpuscular médio, o hematócrito e a hemoglobina. As coletas foram realizadas imediatamente antes da interrupção da gestação. Os resultados nos dois grupos foram comparados pelo teste t de Student, método de amostras pareados pela idade gestacional.

Resultados: não se encontrou diferença nas taxas de folatos fetais e nos parâmetros hematológicos dos fetos, entre os dois grupos. Por outro lado, taxas anormalmente baixas de folatos foram encontradas nos eritrócitos das mães portadoras de fetos com DFTN, tanto para as formas totais $(293,9 \mathrm{ng} / \mathrm{mL}$ contra $399,1 \mathrm{ng} / \mathrm{mL}$ no grupo controle, $p=0,01)$ quanto para as formas metiladas $(201,9 \mathrm{ng} / \mathrm{mL}$ contra $314,0 \mathrm{ng} / \mathrm{mL}$ para o grupo controle, $p=0,02)$. Os folatos séricos maternos não se mostraram diferentes nos grupos estudo e controle.

Conclusão: este estudo demonstrou que há uma menor taxa de folatos intratissulares, nas mães de fetos acometidos por DFTN, porém com taxas de folatos séricos semelhantes em relação ao grupo controle.
\end{abstract}

PALAVRAS-CHAVE: Defeitos do tubo neural. Ácido fólico. Malformações.

Clínica Obstétrica da Faculdade de Medicina da Universidade de São Paulo

Correspondência:

Victor Bunduki

Rua Dr. Enéas de Carvalho Aguiar, 255 - 10ªndar

Cerqueira César - São Paulo - SP

CEP: 05403-000
Introdução

Os defeitos de fechamento do tubo neural (DFTN) são malformações do sistema nervoso central causadas por um desenvolvimento alterado em etapas precoces da embriogênese. A forma mais 
grave e letal destes defeitos é a anencefalia. Outro tipo de DFTN, a espinha bífida aberta, associa-se à paralisia dos membros inferiores, incontinência urinária e fecal e outras incapacitações, incluindo retardo mental que ocorre em aproximadamente $30 \%$ dos casos. A permanência em berçários costuma ser prolongada e o seguimento contínuo deve se estender por toda a vida do paciente.

A incidência global dos DFTN varia em todo o mundo e vai de 1/1000 nascidos vivos até 8/1000 nascidos vivos em regiões de alta prevalência $^{18}$. No Brasil, estima-se em 1,6/1000 nascidos vivos a incidência de $\mathrm{DFTN}^{15}$. O risco de recorrência da patologia em gestantes com antecedente obstétrico de DFTN está estimado em 2 a 3\%, ou seja, cerca de 10 vezes maior que o risco da população geral para a primeira ocorrência $^{16}$.

O ácido fólico age como uma coenzima na síntese e no metabolismo dos ácidos nucléicos. A deficiência de folatos leva a uma alteração da divisão celular que é mais pronunciada em tecidos em crescimento e com alta taxa de multiplicação celular $^{14}$. A demanda de folatos está aumentada durante a gestação. A participação desta vitamina no processo etiológico dos DFTN vem sendo discutida desde $1965^{11}$.

Estudos sobre a ingestão de folatos e sobre concentrações maternas de ácido fólico demonstraram, quase uniformemente, uma relação entre deficiências nutritivas e a recorrência dos DFTN. Estudos do tipo caso-controle demonstraram efeito protetor de altas taxas de folatos intra-eritrocitários maternos ou da elevada ingestão de folatos para a prevenção dos DFTN. O resultados de vários estudos recentes, controlados e aleatórios, confirmaram uma relação causal entre o consumo materno de ácido fólico e a prevenção da recorrência dos DFTN $^{16,21}$.

No entanto, muitos aspectos desta interação entre os folatos e os DFTN permanecem desconhecidos, em particular, de que maneira o ácido fólico agiria para o fechamento do tubo neural e se os niveis séricos de folatos estariam realmente alterados nas gestantes portadoras de fetos com esses defeitos, ou, ainda se existiria uma alteração metabólica para que ocorresse um armazenamento defeituoso de folatos em nível tissular.

Assim, se, do ponto de vista epidemiológico, a suplementação periconcepcional com ácido fólico vem sendo apontada como a primeira oportunidade concreta de prevenir defeitos congênitos desde a vacinação em massa contra a rubéola (iniciada há 20 anos), do ponto de vista de fisiopatologia, metabolismo e quantificação dos niveis de folatos, os dados são controversos quanto ao papel real desta vitamina no desenvolvimento dos DFTN, em especial, para a população geral sem risco particular. A interação entre fatores genéticos e a fisiopatologia dos DFTN é também assunto bastante debatido na literatura e, mesmo após trinta anos do primeiro relato da possivel implicação dos folatos na gênese dos DFTN, o assunto parece longe ainda de ser esgotado ${ }^{19,20,21}$.

Neste contexto, é importante conhecer e analisar os níveis de folatos no soro e células de gestantes com fetos portadores de DFTN, seguindo metodologia de ponta, pois os resultados podem contribuir para a melhor compreensão da dinâmica do metabolismo dos folatos e ajudar no processo de seleção de pacientes com risco elevado para DFTN, dentro de populações ditas de baixo risco.

\section{Material e Métodos}

Neste estudo, a população foi constituída de gestantes que tiveram indicação de interrupção terapêutica da gravidez, sendo o grupo estudo constituído por aquelas com fetos portadores de um DFTN isolado, sem anormalidade de cariótipo e o grupo controle, por outras, com fetos portadores de uma outra malformação que não os DFTN. O estudo foi conduzido na Unidade de Medicina Fetal da Maternidade Port Royal - Hospital Cochin em Paris, França, durante o período de setembro de 1991 a agosto de 1993.

No total, foram analisados 28 casos, 14 casos no grupo estudo e 14, no grupo controle. As malformações fetais do grupo de estudo DFTN foram: 2 casos de anencefalia e 12 casos de espinha bífida, sendo 5 casos com meningomielocele de localização lombar, 6 casos com meningomielocele lombo-sacra e 1 caso com disrafia extensa da coluna. Como grupo controle, foram escolhidas 14 gestantes, cujos fetos apresentaram outras malformações (que não incluíam o tubo neural). As malformações fetais do grupo controle constituíram-se de 6 casos de ventriculomegalia cerebral acentuada, 2 casos de microcefalia, 1 caso de holoprosencefalia alobar, 1 caso de cardiopatia grave (hipoplasia de ventrículo esquerdo), 1 caso de displasia ectodérmica anidrótica, 1 caso de nanismo tanatofórico, 1 caso de síndrome de banda amniótica e 1 caso de polimalformação com hérnia diafragmática, cardiopatia e rins em ferradura. Os casos-controle foram emparelhados, um a um, com os casos de DFTN, única e exclusivamente pela idade gestacional. Foram excluídos os casos nos quais não se pôde obter emparelhamento, com diferença máxima de 7 dias, entre o caso DFTN e o caso-controle.

Foram incluídas neste estudo somente as 
mulheres sem antecedente de feto acometido por DFTN e que não tivessem feito uso prévio de medicamentos contendo ácido fólico ou outras vitaminas.

Foram dosados os folatos séricos totais e suas formas metiladas, assim como os folatos intraeritrocitários totais e suas formas metiladas, nas mães e nos fetos. Os níveis de folato foram medidos microbiologicamente, usando Lactobacillus casei, cujo crescimento é dependente de todas as formas de folato no meio de cultura e Streptococcus faecalis, que requer, para seu crescimento, todas as formas de folato exceto o metiltetraidrofolato. As formas metiladas foram estimadas como a diferença entre medidas obtidas com $L$. casei e $S$. faecalis e consistem principalmente em 5-metiltetraidrofolato, que é o metabólito biologicamente ativo do ácido fólico. A razão de metilação do folato no soro e nos eritrócitos foi definida como a razão entre as formas metiladas e a concentração total de folato e foi expressa em porcentagem. Esta abordagem foi possível graças à colaboração do Laboratório Central de Microbiologia do Hospital Henri Mondor, Paris, França.

Foram também determinadas a hemoglobina (Hb), o volume corpuscular médio (VCM) e o hematócrito (Ht) fetais e maternos. Estes parâmetros hematológicos foram obtidos utilizando um contador Coulter (Counter S - Plus IV, Coulter Electronics, Inglaterra). As dosagens biológicas (medições e contagens sangüineas) foram realizadas no laboratório de hematologia perinatal do Hospital Saint Vincent de Paul (Universidade de Paris V).

A coleta do sangue materno foi realizada por punção venosa simples, na sala de procedimentos, imediatamente antes da coleta de sangue fetal. A coleta de sangue fetal foi realizada imediatamente antes da interrupção da gestação, por meio de punção com uma agulha longa, 20 Gauge, sob orientação ultra-sonográfica, e posicionada na cavidade cardíaca do feto, de onde foi colhido o sangue fetal para as dosagens. A pureza do sangue fetal, isto é, a ausência de mistura com líquido amniótico ou sangue materno foi testada usandose o teste de Kleihauer e, ainda, o teste da relação de hCG sérico fetal/materno.

O estudo anátomo-patológico do feto foi realizado em todos os casos, após a expulsão do mesmos.

O protocolo de estudo do presente trabalho foi aprovado pelo Comitê de Ética Médica do Hospital COCHIN-Maternidade Port-Royal da Universidade de Paris V, René Descartes.

As concentrações de folato e os índices hematológicos nos dois grupos foram comparados pelo teste t de Student para cálculo do valor de $\mathrm{p}$, com amostras emparelhadas, uma a uma, pela idade gestacional, usando o programa estatístico Stat View (ABACUS, Califórnia - E.U.A.). Foram consideradas diferentes, do ponto de vista estatístico, as médias comparadas, cujos valores de $\mathrm{p}$ fossem menores ou iguais a 0,05. Uma segunda abordagem estatística, usada somente para as dosagens de folatos, constituiu-se no estudo da correlação entre os diferentes parâmetros estudados, pelo cálculo do valor de $r$ (teste de correlação de Spearman - programa Stat View ABACUS, Califórnia - E.U.A.).

\section{Resultados}

As coletas das amostras de sangue foram realizadas entre 20 e 36 semanas de idade gestacional, para os dois grupos, com uma média de 28,7 $\pm 5,0$ semanas, no grupo de DFTN e $28,7 \pm 5,5$ semanas, no grupo controle. A diferença média de idade gestacional, entre os dois grupos, no momento da coleta, foi de 5,5 dias, não excedendo uma semana.

Não foram encontradas diferenças estatisticamente significativas entre os dois grupos de mães, no que diz respeito às taxas de hemoglobina (média no grupo de DFTN $=12,0 \mathrm{~g}$ / $\mathrm{dL}$ e média no grupo controle $=11,9 \mathrm{~g} / \mathrm{dL}$ ), hematócrito (média no grupo de DFTN $=35,1 \%$ e no grupo controle $=34,9 \%$ ) e volume corpuscular médio (média no grupo de DFTN=90,3 fL e média do grupo controle $=92,7 \mathrm{fL}$ ).

A Tabela 1 indica os resultados maternos para as dosagens de folatos nos dois grupos. Foram encontradas diferenças significativas, entre os dois grupos, em relação aos folatos eritrocitários maternos totais $(293,9 \mathrm{ng} / \mathrm{mL} \pm 26,1$ para o grupo de DFTN contra $399,1 \mathrm{ng} / \mathrm{mL} \pm 37,3$ no grupo controle; $\mathrm{p}=0,01)$ e metilados $(201,9 \mathrm{ng} / \mathrm{mL} \pm 27,8$ para o grupo de DFTN contra $314,0 \mathrm{ng} / \mathrm{mL} \pm 38,0$ no grupo controle; $p=0,02$ ). No entanto, não foram encontradas diferenças estatisticamente significativas entre os dois grupos, no que diz respeito aos folatos séricos maternos.

A taxa de metilação de folatos nos glóbulos vermelhos maternos não foi estatisticamente diferente nos dois grupos, com 68\% de formas metiladas no grupo DFTN e 73\% de metilação no grupo controle $(p=0,31)$. Foi verificada significativa correlação entre o nível das formas metiladas com a taxa total de folatos nos eritrócitos maternos, quando testados pelo coeficiente de correlação de Spearman. O valor encontrado de $\mathrm{r}$ foi 0,98 para o grupo DFTN e 0,97 para o grupo controle. 
Os testes de Kleihauer e da relação fetomaterna de hCG resultaram em 100\% de pureza do sangue fetal nas amostras.

Não foram encontradas diferenças estatisticamente significativas, entre os dois grupos de fetos, no que concerne às taxas de hemoglobina (média no grupo de DFTN $=12,5 \mathrm{~g} / \mathrm{dL}$ e média no grupo controle $=12,8 \mathrm{~g} / \mathrm{dL}$ ), hematócrito (média no grupo de DFTN $=36,7 \%$ e no grupo controle $=$ $37,3 \%$ ) e volume corpuscular médio (média no grupo de DFTN= 86,8 unidades e média do grupo controle $=92,7$ ).

Tabela 1 - Médias, desvios padrão e valores de $p$ dos folatos maternos no grupo de DFTN e no grupo controle Paris, 1991-1993

\begin{tabular}{|c|c|c|c|c|c|}
\hline & \multicolumn{2}{|c|}{ DFTN } & \multicolumn{2}{|c|}{ CONTROLE } & \multirow[b]{2}{*}{$\mathrm{p}$} \\
\hline & Média & $\begin{array}{l}\text { Desvio } \\
\text { padrão }\end{array}$ & Média & $\begin{array}{l}\text { Desvio } \\
\text { padrão }\end{array}$ & \\
\hline FET (ng/mL) & 293,9 & 26,1 & 399,1 & 37,3 & 0,01 \\
\hline FEM (ng/mL) & 201,9 & 27,8 & 314,0 & 38,0 & 0,02 \\
\hline FST(ng/mL) & 8,4 & 0,9 & 9,9 & 1,6 & 0,48 \\
\hline FSM (ng/mL) & 5,2 & 1,0 & 6,6 & 1,5 & 0,60 \\
\hline
\end{tabular}

DFTN = defeitos de fechamento do tubo neural;

FET = folatos eritrocitários totais;

FEM = folatos eritrocitários metilados;

$\mathrm{FST}=$ folatos séricos totais;

$\mathrm{FSM}=$ folatos séricos metilados

A Tabela 2 indica os resultados fetais para as dosagens de folatos. Em todos os parâmetros concernentes aos folatos fetais, não foram encontradas diferenças estatisticamente significativas entre os dois grupos, tanto no caso dos folatos séricos totais $(p=0,25)$ e metilados $(p=0,18)$, quanto no caso dos folatos eritrocitários totais $(p=0,41)$ e metilados $(p=0,57)$.

A Tabela 3 mostra os resultados comparativos entre os fetos e as mães para as diferentes dosagens de folatos no grupo com DFTN. A média de folatos nos fetos acometidos por um DFTN foi invariavelmente mais elevada que nas suas mães (folatos séricos totais: $15,7 \mathrm{ng} / \mathrm{mL} \pm 1,1$ contra 8,4 $\mathrm{ng} / \mathrm{mL} \pm 3,4 ; \mathrm{p}=0,000$; folatos séricos metilados: $11,4 \mathrm{ng} / \mathrm{mL} \pm 1,3$ contra $5,2 \pm 1,0 ; \mathrm{p}=0,001$; folatos eritrocitários totais: $445,3 \mathrm{ng} / \mathrm{mL} \pm 39,1$ contra $293,9 \mathrm{ng} / \mathrm{mL} \pm 26,1 ; \mathrm{p}=0,035$ e folatos eritrocitários metilados: $310,9 \mathrm{ng} / \mathrm{mL} \pm 44,1$ contra $201,9 \mathrm{ng} / \mathrm{mL} \pm 27,8 ; \mathrm{p}=0,040$ ).

As taxas de folatos fetais séricos, assim como os fetais eritrocitários, tanto para as formas totais quanto para as metiladas, foram independentes das taxas maternas séricas para os dois grupos, quando testadas pelo coeficiente de correlação de Spearman, com valores de $r$ menores que 0,6 para todos os parâmetros.

Os resultados da análise anátomo-patológica dos fetos confirmaram todos os casos de DFTN, assim como as outras malformações não acompanhadas de DFTN, incluídas no grupo controle.

Tabela 2 - Médias, desvios padrão e valores de $p$ dos folatos fetais no grupo de DFTN e no grupo controle, Paris, 1991-1993

\begin{tabular}{lrrrrr}
\hline & \multicolumn{2}{c}{ DFTN } & \multicolumn{2}{c}{ CONTROLE } & \\
\cline { 2 - 5 } & Média & Desvio & Média & Desvio & p \\
& & padrão & & padrão & \\
\hline FET (ng/mL) & 445,3 & 39,1 & 485,1 & 45,1 & 0,41 \\
FEM (ng/mL) & 310,9 & 44,1 & 353,8 & 38,0 & 0,57 \\
FST(ng/mL) & 15,7 & 1,1 & 19,1 & 2,8 & 0,25 \\
FSM (ng/mL) & 11,4 & 1,3 & 15,2 & 2,6 & 0,18 \\
\hline
\end{tabular}

DFTN = defeitos de fechamento do tubo neural;

$\mathrm{FET}=$ folatos eritrocitários totais;

FEM = folatos eritrocitários metilados;

FST = folatos séricos totais;

$\mathrm{FSM}=$ folatos séricos metilados

Tabela 3 - Média, desvios padrão e valores de $p$ dos folatos matrenos e fetais no grupo de DFTN, Paris, 1991-1993

\begin{tabular}{|c|c|c|c|c|c|}
\hline & \multicolumn{2}{|c|}{ DFTN } & \multicolumn{2}{|c|}{ CONTROLE } & \multirow[b]{2}{*}{$\mathrm{p}$} \\
\hline & Média & $\begin{array}{l}\text { Desvio } \\
\text { padrão }\end{array}$ & Média & $\begin{array}{l}\text { Desvio } \\
\text { padrão }\end{array}$ & \\
\hline FET (ng/mL) & 445,3 & 39,1 & 293,9 & 26,1 & 0,035 \\
\hline FEM (ng/mL) & 310,9 & 44,1 & 201,9 & 27,8 & 0,040 \\
\hline $\mathrm{FST}(\mathrm{ng} / \mathrm{mL})$ & 15,7 & 1,1 & 8,4 & 3,4 & 0,000 \\
\hline FSM (ng/mL) & 11,4 & 1,3 & 5,2 & 1,0 & 0,001 \\
\hline
\end{tabular}

DFTN = defeitos de fechamento do tubo neural;

$\mathrm{FET}=$ folatos eritrocitários totais;

FEM = folatos eritrocitários metilados;

FST = folatos séricos totais;

$\mathrm{FSM}=$ folatos séricos metilados

\section{Discussão}

Este trabalho teve como objetivo comparar os niveis maternos e fetais de folatos, no segundo e terceiro trimestres de gravidez, em gestantes com fetos portadores de DFTN e de fetos controles. A 
comparabilidade dos dois grupos foi assegurada, ao nosso ver, de forma satisfatória, por meio de um emparelhamento pela idade gestacional. De fato, as taxas de ácido fólico materno tendem a cair progressivamente com a idade gestacional, o que poderia falsear os resultados, caso não fosse realizado um verdadeiro emparelhamento. Assim, em razão da tendência de queda dos níveis maternos de folato, durante a gestação ${ }^{9}$, comparar casos de DFTN com controles de idades gestacionais similares contribuiu para aumentar a sensibilidade de nossos resultados.

A carência de ácido fólico é correlacionada com o volume eritrocitário e causa macrocitose. Quanto aos dados hematológicos, não foram observadas anomalias de volume corpuscular médio (VCM) nas mães de fetos acometidos por um DFTN. Neste estudo, as mães dos fetos acometidos por DFTN não apresentaram níveis significativamente mais baixos de folatos séricos (sejam eles metilados ou totais) em relação aos do grupo controle. Isso está de acordo com os dados de outros autores ${ }^{8,13,14}$, que afirmam que um nível sérico de folatos reduzido não é um fator para aumento de risco para os DFTN quando se trata de populações ditas de baixo risco. Esta observação sugere a ausência de carência de aporte nas mães.

No entanto, as mães de fetos acometidos por DFTN apresentaram, neste estudo, nivel mais baixo de folatos intra-eritrocitários (tanto metilados quanto totais) que o grupo controle. Na literatura, as taxas de folato eritrocitários das mães de crianças com DFTN vêm sendo descritas como sendo mais baixas ${ }^{16,19}$ ou semelhantes ${ }^{3,8,11}$, quando comparadas com os casos controle. Para esclarecer as diferenças de resultados, entre nosso estudo e aqueles de autores como Mills et al. ${ }^{16}$, Holzgreve et al. ${ }^{12}$, Bower e Stanley ${ }^{3}$, que não encontraram diferenças entre as taxas de folatos eritrocitários nas gestantes com crianças afetadas por um DFTN, pode-se pensar em alguns fatores de viés potencial, como a idade gestacional escolhida, sem emparelhamento, ou talvez, dosagens realizadas em idades gestacionais mais tardias ou mesmo a possibilidade de que alguns casos descritos por estes autores não sejam associados ao ácido fólico ${ }^{6}$. O número de casos estudados tem sido, em geral, pequeno e, por vezes, foram incluídos alguns casos que não correspondiam aos DFTN ${ }^{13}$. As diferenças, que não foram estatisticamente significativas, podem se dever ao reduzido número de $\operatorname{casos}^{8}$. A coleta das amostras foi freqüentemente realizada tardiamente na gestação (ao fim do terceiro trimestre, quando fisiologicamente os folatos variam mais), sem emparelhar os casos pela idade gestacional e, algumas vezes, após o parto. Algumas mulheres, que tinham utilizado suplementos vitamínicos via oral, foram analisadas sem levar em conta a relação com a embriologia do fechamento do tubo neural e a idade gestacional ${ }^{15}$.

Por outro lado, as dificuldades de se obter dosagens de folatos maternos, em uma idade gestacional que corresponda ao momento do fechamento do tubo neural, são enormes e talvez não possam ser vencidas já que não se pode saber se o feto está afetado por DFTN, antes da décima terceira semana, pelas técnicas de ultra-sonografia transvaginal (ou, antes da décima oitava à vigésima semana, pela ultra-sonografia transabdominal). Asseguraria resultados adequados, a obtenção de dosagens entre zero e seis semanas do período embrionário, pois o embrião deve estar vulnerável, somente neste período particular da embriogênese. Esta metodologia de estudo, porém, seria difícil de ser realizada. De qualquer maneira, em 1972, Hall $^{10}$ em seu importante estudo sobre a teratogênese, pôde dosar os folatos séricos maternos no primeiro trimestre da gestação e não encontrou associação entre um nível baixo de folatos séricos maternos e as malformações.

No presente estudo, foram descartados (por interrogatórios pessoais) os antecedentes familiares, pessoais e obstétricos positivos, assim como a ingestão de medicamentos ou de vitaminas e de álcool. Quanto à dependência entre os níveis maternos e fetais de folatos, observamos que não há correlação entre os dois compartimentos e os fetos apresentaram níveis normais de folatos, mesmo nos casos de mães com folatos eritrocitários totais e folatos eritrocitários metilados mais baixos. Sustentados por nossos resultados e analisando os diferentes coeficientes de correlação entre os folatos maternos e fetais, podemos inferir que uma anormalidade de transferência transplacentária de folatos parece não estar envolvida na patogênese dos DFTN ${ }^{4}$.

O fato de haver encontrado níveis mais baixos de folatos eritrocitários nas mães de fetos afetados por DFTN, mas sem diferença em seus niveis séricos, é bastante sugestivo de um defeito no metabolismo de folatos e não de carência de ingestão, visto que o folato sérico é um indicador mais precoce de carência de folatos que a taxa eritrocitária ${ }^{13}$. Esta última é considerada como um indicador, a longo termo, do estado global de folatos $^{5,17}$.

Os nossos resultados, aliados à metodologia utilizada nos interrogatórios para selecionar somente pacientes sem sinais de carência alimentar, nos permite assegurar que estas gestantes não tinham deficiência de aporte nutricional de folatos. Para o controle da pureza do sangue fetal obtido, utilizamos a confirmação da qualidade da amostra, por meio dos testes de 
Kleihauer e do teste da relação do hCG sérico fetal, comparado com o hCG sérico materno. O teste de Kleihauer detecta contaminações iguais ou superiores a $0,5 \%$ e o teste do hCG é um pouco mais sensivel e detecta contaminações maiores ou iguais a $0,2 \%{ }^{7}$. Esses testes, aliados ao fato de as coletas terem sido realizadas por punção intracardíaca, nos permitem afirmar que o sangue fetal obtido era $100 \%$ puro.

Não foi encontrada nenhuma diferença nas dosagens de folatos fetais, assim como nas dosagens hematológicas, entre os dois grupos de fetos, o que está de acordo com as poucas contribuições existentes na literatura. Com efeito, os trabalhos sobre as dosagens de folatos fetais são raros na literatura e, além do presente estudo, encontramos publicados apenas dois artigos que fornecem informações sobre o assunto ${ }^{8,11}$.

A análise dos nossos resultados não permite avaliar a possibilidade de deficiência transitória de folato fetal, em um estágio precoce do desenvolvimento, quando ocorre o fechamento do tubo neural. Pouco se conhece ainda sobre a passagem de substratos do meio materno para o fetal, nas etapas pré-placentárias da gestação ${ }^{18}$. Sabemos que não há interface hemocorial em etapas embrionárias precoces, e as necessidades do embrião possivelmente seriam supridas pelas próprias reservas do ovo.

Se baixas taxas tissulares de ácido fólico existem para as mães de fetos acometidos por DFTN, como indicam nossos resultados, podemos conjecturar que todas as células maternas teriam níveis baixos de folato, incluindo os oócitos. Sabemos que o armazenamento de substrato para as necessidades embrionárias, nos primeiros dias do ovo, é de responsabilidade do oócito, já que o espermatozóide praticamente não carrega reservas, só material genômico. Poder-se-ia supor que as mesmas causas para baixos niveis de folatos nos eritrócitos maternos, estariam presentes também nos oócitos, portanto, antes da fecundação. Infelizmente, o único tecido utilizado, na prática, para a dosagem de folatos intracelulares é o sangue, pelo conteúdo eritrocitário e não poderíamos atualmente dosar os folatos, nos oócitos, após a sua coleta.

Alguns autores ${ }^{1,9}$ têm demonstrado que as taxas de folatos fetais são mais elevadas que as taxas maternas, observações estas corroboradas por este estudo. $O$ fato de se encontrar sempre um nível de folatos mais elevado no feto demonstra que existem mecanismos, provavelmente de transporte ativo, para garantir o aporte desta vitamina para o feto. De fato, um fator específico que assegura o acesso fetal às reservas de folatos as proteínas portadoras de folatos - foi bem demonstrado na placenta ${ }^{1,9,12}$, mas essa função foi apresentada tardiamente e já na etapa placentária da gestação. Outra questão, ainda em aberto, e, ao que parece, de extrema complexidade, é a caracterização dos receptores de folatos e o entendimento do seu mecanismo de ação ${ }^{2}$.

Com nosso trabalho, não encontramos níveis diferentes de folatos séricos, tanto totais quanto metilados, nas gestantes do grupo de fetos com DFTN. Niveis significativamente mais baixos de folatos eritrocitários, tanto totais quanto metilados, foram encontrados nas gestantes com fetos acometidos por DFTN, quando comparados com os das gestantes do grupo controle. Também não houve diferenças significativas nos niveis de folatos fetais entre os dois grupos. Estes fatos indicam anormalidade do metabolismo ou do processo de estocagem dos folatos nas gestantes com fetos portadores de DFTN. Tendo em vista os resultados deste estudo, podemos concluir que, para estimar o risco de DFTN, devemos efetuar dosagens de folatos intratissulares. A dosagem sérica periférica simples induz a resultados falso-negativos.

\section{Agradecimentos}

Ao Prof. Joelle Zittoun (Laboratório Central de Microbiologia do Hospital Henri Mondor, Paris, França), pelas dosagens microbiológicas dos folatos neste trabalho e também ao Prof. A. Sender (Laboratório de Hematologia Perinatal do Hospital Saint Vincent de Paul, Paris, França), por ter realizado as dosagens dos parâmetros hematológicos.

\section{SUMMARY}

Objective: to analyze maternal and fetal folate status in cases of neural tube defects (NTD).

Methods: a case-control study was designed with 14 cases of fetuses with neural tube defects (study group) and 14 cases of fetuses with other unrelated malformations (control group) gestational age matched, in low-risk pregnant women. Both total and methylated folic acid levels in fetal and maternal compartments using serum and tissular (red blood cells) concentrations and also average corpuscular volume, hematocrit and hemoglobin levels were determined. Fetal and maternal samples were obtained immediately before termination of pregnancy. Results in both groups were compared using a gestational age paired t-test.

Results: there were no statistically significant differences in fetal folate levels and fetal hematologic parameters between 
both groups However, both total (239.9 $\mathrm{ng} / \mathrm{mL}$ in NTD against $399.1 \mathrm{ng} / \mathrm{mL}$ in control group, $p=0.01)$ and methylated $(201.9$ $\mathrm{ng} / \mathrm{mL}$ in NTD against $314.0 \mathrm{ng} / \mathrm{mL}$ in control group, $p=0.02$ ) maternal red blood cells folate levels were significantly lower in the neural tube defect group. Maternal serum folate levels were similar in study and control groups.

Conclusion: this study showed that maternal red blood cell folate but not serum folate was significantly reduced in mothers offetuses with neural tube defects.

KEY WORDS: Neural tube defects. Folic acid.

\section{Referências}

1. Antony AC, Utley C, Van Horne K C, Kolhouse JF. Isolation and characterisation of a folate receptor from human placenta. J Biol Chem 1981; 256:9684-92.

2. Antony AC. The biological chemistry of folate receptors. Blood 1992; 79:2807-20.

3. Bower C, Stanley FJ. Dietary folate as a risk for neural tube defects: evidence from a case-control study in western Australia. Med J Aust 1989; 150:613-9.

4. Bunduki V, Dommergues M, Zittoun J, Marquet J, Muller F, Dumez Y. Maternal-fetal folate status and neural tube defects: A case control study. Biol Neonate 1995, 67:154-59.

5.Carmel R. Diagnostic des anémies mégaloblastiques.In: Progrès en Hematologie. Paris: Masson; 1987. p. 87-95.

6. Daly LE, Kirke PN, Molloy A, Weir DG, Scott JM. Folate levels and neural tube defects. Implications for prevention. JAMA 1995; 274:1698-702.

7. Dommergues M, Bunduki V, Muller F, Mandelbrot L, Morichon-Delvallez N, Dumez Y. Serum hCG assay: A method for detection of contamination of fetal blood samples. Prenat Diagn 1993; 13:1043-6.

8. Economides DL, Ferguson J, Mackenzie IZ, Darley J, Ware II, Holmes-Siedle M. Folate and vitamin B12 concentrations in maternal and fetal blood, and amniotic fluid in second trimester pregnancies complicated by neural tube defects. Br J Obstet Gynaecol 1992; 99:23-5.

9. Giugliani ERJ, Jorge SM, Gonçalves AL. Serum and red blood cell folate levels in parturients in the intervillous space of the placenta and in full-term newborns. J Perinat Med 1985; 13:55-59.

10. Hall MH. Folic acid deficiency and congenital malformation. J Obstet Gynaecol Br Com 1972; 79:159-61.

11.Hibbard ED, Smithells RW. Folic acid metabolism and human embryopathy. Lancet 1965; 312:1254.

12.Holzgreve W, Tercanli S, Pietrzik K, Jukes TH. Erythrocyte folate in fetal blood. Lancet 1991; 338:640.

13.Landon MJ, Eyre DH, Hytten FE. Transfer of folate to the fetus. Br J Obstet Gynaecol 1975; 82:12-9.

14.Lehninger A L. Vitamines e coenzymes. In: Worth editor. Biochimie. Paris: 1991. p. 340-7.

15. Matushita H, Almeida GM. Disrafismos craniano e espinhal. In: editores Pediatria Básica. São Paulo: Sarvier; 1991. p. 115-19.

16.Mills JL, Tuomilehto J, Yu KF, Colman N, Blaner WS, Koskela P, et al. Maternal vitamin levels during pregnancies producing infants with neural tube defects. J Pediatr 1992; 120:863-71.

17.Molloy AM, Kirke P, Hillary DG,.Scott JM. Maternal serum folate and vitamin B12 concentrations in pregnancies associated with neural tube defects. Arch Dis Child 1985; 60:660-5.

18.Pérez-Escamilla R. Periconceptional folic acid and neural tube defects: Public health issues. Bulletin of PAHO 1995; 29:250-61.

19.Rosenberg IH. Folic acid and neural-tube defects -Time for action. N Engl J Med 1992; 327:1875-7.

20.Sheppard S, Nevin NC, Seller MJ, Wild J, Smithells RW, Read AP, et al. Neural tube defect recurrence after "partial" vitamin supplementation. J Med Genet 1989; 26: 326-9.

21.Smithells RW, Sheppard S, Schorah CJ. Vitamin deficiencies and neural tube defects. Arch Dis Child 1976; 51:944-50. 